\title{
The Sharing Economy and the Future of Personal Mobility: New Models Based on Car Sharing

\author{
Olga Novikova
}

\author{
"You cannot separate the buildings out from the") \\ infrastructure of cities and the mobility of transit. \\ Norman Foster \\ The Rt Hon. The Lord Foster of Thames Bank, OM \\ Architect
}

\begin{abstract}
The sharing economy is an emerging phenomenon that shapes the cultural, economic, and social landscape of our modern world. With variations of the concept of the sharing economy emerging in so many fields, the area of shared mobility - the shared use of a motor vehicle, bicycle, or other mode that enables travellers to gain short-term access to transportation modes on an on-demand basis - has developed as the forerunner of the transformation to be expected in other areas. This article examines how the sphere of personal mobility has been affected by the growth of sharing economy. It contributes to the growing body of shared mobility literature by uncovering innovative mobilitybased models that represent solutions on the intersection of shared mobility, physical infrastructure, and integrated-mobility schemes.
\end{abstract}

\section{Introduction}

During the last decade, the concept of the sharing economy has entered various industries and has altered numerous aspects of daily life. The general notion of sharing within the society is not new (Belk, 2007, 2010, 2014), however, the evolution of the Internet has enabled sharing to spread beyond the local interaction and facilitated connection between vast amounts of individuals (Belk, 2014; Botsman \& Rogers, 2010; Hamari et al., 2016).

Various definitions of the sharing economy have been put forward in recent years, however, no single description has been widely accepted by research and practitioner communities (Botsman, 2013). For example, Botsman and Rogers (2010) broadly define the sharing economy or collaborative consumption as "traditional sharing, bartering, lending, trading, renting, gifting, and swapping, redefined through technology and peer communities".

Applications of the sharing economy concept have found their way into various areas. In the area of production, the sharing economy is manifested in the design, production, and distribution of goods through collaborative networks, with examples including the TechShop (techshop.ws) workshop and fabrication studio and the Quirky (quirky.com) invention platform (Bauwens et al., 2012; Botsman, 2013). In consumption, it means maximizing the utilization of assets through efficient models of redistribution and shared access, as seen with the Zipcar (zipcar.com) car-sharing service, Airbnb's (airbnb.com) accommodation marketplace, and the Lyft (lyft.com) transportation network (Botsman, 2013). In finance, the collaborative economy means person-to-person banking and crowd-driven investment models that decentralize finance, with examples including the Zopa (zopa.com) peer-to-peer lending platform and the Kickstarter (kickstarter.com) funding platform for creative projects (Botsman, 2013; Owyang \& Samuel, 2015). In education, the collaborative economy implies open education and person-to-person learning models that democratize education, with examples including the Coursera (coursera.org) online course platform and the Skillshare (skillshare.com) online learning community (Bauwens et al., 2012; Botsman, 2014).

With variations of the concept of the sharing economy emerging in so many fields, the area of shared mobility - the shared use of a motor vehicle, bicycle, or other mode that enables travellers to gain short-term access 


\section{The Sharing Economy and the Future of Personal Mobility Olga Novikova}

to transportation modes on an on-demand basis - has developed as the forerunner of the transformation to be expected in other areas (Le Vine \& Pollak, 2015; Shaheen \& Chan, 2016). Thus, there has been a growing interest in the topic among researchers of mobility in recent years. Researchers have focused their attention on the evolution of car sharing (Shaheen et al., 2015), the technological aspects of the car-sharing market (Zoepf \& Keith, 2016), the behaviours and motivations of carpooling service users (Shaheen et al., 2016), mobility business models for the sharing economy (Cohen \& Kietzman, 2014), and the concept of mobility as a service (Expósito-Izquierdo et al., 2017), among other topics.

Whereas research to date has focused on the existing characteristics of shared mobility, there is lack of understanding of what kind of new mobility models emerge with the advance of the sharing economy. It is also unclear what solutions appear on the intersection of shared mobility, physical infrastructure, and integratedmobility schemes. This study attempts to uncover the emerging innovative mobility models, based on the interviews collected with mobility experts, business owners of car-sharing companies, and users of shared mobility solutions.

This article is structured as follows. First, it gives an account of research on car-sharing, ride-sharing, and other shared mobility modes. Then, based on the data collected for this study, it showcases new models emerging on the intersection of the sharing economy and the traditional economy. Finally, it offers a model illustrating an integrated mobility solution.

\section{Mobility in the Sharing Economy}

One of the perhaps most recognized and widespread applications of the sharing economy has emerged in the area of personal mobility through car sharing (Botsman \& Rogers, 2010; Cohen \& Kietzman, 2014). As with sharing itself, car sharing is not a new phenomenon. Car sharing emerged in the 1950s when membership was primarily motivated by economics (Shaheen et al., 1998), and it has since continued its worldwide growth (Shaheen \& Cohen, 2007). With car sharing, individuals gain the benefits of using private cars without the costs and responsibilities of car ownership (Shaheen et al., 1998). Thus, instead of owning one or more vehicles, a household accesses a fleet of vehicles on an as-needed basis. Car sharing may be thought of as organized recurring short-term car rental. Individuals gain access to a car-sharing service by joining organizations that main- tain a fleet of cars in a network of vehicle locations. Generally, participants pay a modest fixed charge plus a usage fee each time they use a vehicle (Shaheen et al, 1998; Shaheen \& Cohen, 2013). The impacts of car sharing can be categorized as environmental, land use, social effects, and transportation (Shaheen \& Cohen, 2013).

Several possible typologies of car sharing have been identified (Bauwens et al., 2012; Cohen \& Kietzman, 2014; Shaheen et al., 1998). For example, Bauwens (2012) differentiates between peer-to-peer car sharing, business-to-consumer car sharing, and non-profit cooperatives. Peer-to-peer (or consumer-to-consumer) car sharing implies that the fleet of cars is owned by a community. The marketplace then matches cars that are available by the owners with the prospective drivers willing to rent them. Companies such as Turo (formerly RelayRides), Getaround, and JustShareIt offer examples of peer-to-peer car sharing. Business-to-consumer car sharing means that a company owns a fleet of cars and facilitates the sharing among members. Auto manufacturers (e.g., BMW, Peugeot, Daimler), rental brands (e.g., Hertz, WeCar), and car-sharing brands (e.g., Zipcar, StattAuto, GoGet) offer examples of business-toconsumer car sharing. Nonprofit cooperatives (or public initiatives) involve a local organization or community that facilitates car sharing with the goal of changing driving habits over making a profit. Organizations such as City Car Share, PhillyCarShare, and Autolib are examples of such initiatives.

Another case of sharing economy that shapes the personal mobility space is ride sharing (or ride hailing vehicle owners allowing other passengers to ride in the same vehicle to and from the same or similar destinations), with Uber being the most prominent example of a platform enabling peer-to-peer transactions (Cohen \& Kietzmann, 2014). Similarly, various dynamic rideshare systems aim to bring together travellers with similar schedules and itineraries on short notice. As Agatz and colleagues (2012) note, new dynamic ride-sharing systems have the potential to provide significant societ$\mathrm{al}$ and environmental benefits by reducing the number of cars used for personal travel and improving the utilization of available seat capacity.

Overall, three factors seem to contribute to the ongoing worldwide growth in shared-use vehicle membership: i) cost savings; ii) convenience of locations, use, and access; and iii) environmental awareness (Shaheen \& Cohen (2013). 


\section{The Sharing Economy and the Future of Personal Mobility Olga Novikova}

\section{Method}

The author studied sharing mobility solutions as part of a larger project examining an emerging electric vehicle ecosystem in Finland. In the first stage, the author collected documents and media material to identify the actors involved in shared mobility and to understand their roles.

In the second stage (March 2012 - August 2013), the author conducted 32 open-ended interviews with a carsharing organization and actors that were the most relevant with regard to the shared mobility solutions, including car-sharing service users, business owners, and mobility experts. In the third stage (March 2012 - May 2014), the author assessed additional documents and media reports to ensure continuous support for ideas development.

The qualitative nature of the study implies its limitations in scope, scale, and replicability. However, it helps shed light on the emerging and previously not captured phenomena in the fast developing field of the sharing economy. Despite its relative maturity, the collected data is still relevant as it projects the anticipated future mobility models.

As typical in qualitative research, the data analysis consisted of multiple iterative and overlapping phases (Yin, 1994). In the first phase, open coding of the interviews was carried out in order to identify important issues relating to mobility solutions in the sharing economy. This helped to identify the new emerging models and a version of an integrated mobility solution after coding more systematically in phase two.

\section{Findings and Discussion}

The present study has identified several innovative models in the space of shared mobility. They combine existing actors in the sharing mobility space and the traditional economy in a novel manner and present an attractive opportunity for future service providers. The findings are summarized in Table 1.

For existing car manufacturers, the sharing economy space offers interesting solutions, such as "lease-toshare" model, whereby a system is created for a leased vehicle to be seamlessly integrated into a shared mobility mechanism. Also, the car-sharing business model for car-manufacturers offers an attractive intermediate solution to address a growing trend of not owning a car. Another noteworthy model emphasizes collaboration between mobility providers with actors in a non-mobility space, such as real-estate developers, whereby the shared mobility solutions are taken into consideration before constructing commercial or residential properties. New technological advances, such as selfdriving cars will bring about flexibility, or, as one of the interviewees put it "fluidity" in the mobility system, whereby the new system will be private in terms of user experience and public in terms of system access. Finally, the industry will see a change toward offering integrated mobility schemes and systems versus current individual mobility solutions.

Based on the interviews, three factors appeared to be crucial in affecting the choice of mobility solution:

\section{Time: defined as total time taken to accomplish a trip}

2. Cost: defined as total cost of a trip

3. Convenience: defined as a perceived convenience of a trip

An integrated mobility solution provides an on-demand single-point-of-purchase tool that will enable a user to reach a desired destination by using any combination of transportation modes, such as public, private, and shared vehicles. The architecture will take into account a user's preferences in terms of time, cost, and perceived convenience of the trip. Furthermore, the variety of payment systems (for example, pre-paid or pay-as-you-go) can be integrated to serve the needs of individual users.

New technological mobility systems may provide significant societal and environmental benefits by reducing the number of cars used for personal travel and improving the utilization of available seat capacity. Technology will play a major role in matching needs and requirements of drivers and riders in real time (Agatz et al., 2012). It will also play a major role in providing a seamless solution for a traveller who would be able to choose a trip based on their preferences regarding time, cost, and convenience while integrating public, private, and shared modes of transportation.

\section{Conclusion}

The sharing economy has been affecting various spheres of our daily lives, and it has made notable progress in the field of mobility services. This article contributes to the growing body of shared mobility literature by uncovering innovative mobility-based 


\section{The Sharing Economy and the Future of Personal Mobility Olga Novikova}

models that represent solutions on the intersection of shared mobility, physical infrastructure, and integratedmobility schemes. Furthermore, an outline of an integrated mobility solution where three factors influencing a user's choice of mobility mode - time, cost, and per- ceived convenience of the trip - are incorporated into a scheme with public, private, and shared modes of transportation, is presented as a technological answer to the future transportation challenges.

Table 1. New models based on sharing

\begin{tabular}{ll}
\hline Type & Description \\
\hline $\begin{array}{l}\text { Lease-to-share } \\
\text { model }\end{array}$ & $\begin{array}{l}\text { "'Lease to share' as a car-sharing model is based on leasing. It is you and me leasing the } \\
\text { car and subletting unused capacity. We are driving new cars, but we are getting them at } \\
\text { a much more attractive rate. You are not responsible to carry the full depreciation load } \\
\text { yourself, but you are sharing it with the group of people who are sharing cars. It makes } \\
\text { a lot of sense, because we are getting out of an ownership model that has implications } \\
\text { for leasing as you can be more flexible with a leasing contract than with owning car." }\end{array}$ \\
\hline $\begin{array}{l}\text { Car-sharing } \\
\text { business model } \\
\text { for car } \\
\text { manufacturers }\end{array}$ & $\begin{array}{l}\text { "The dynamics are different- big players such as Mercedes-Benz, BMW... Fiat is } \\
\text { planning their own car, Vw launched their own car - it is an industry for car } \\
\text { will provide car sharing in different cities and different countries, car sharing with } \\
\text { electric cars. And car sharing will be the first point for the consumer to get to know the } \\
\text { product, and later buy one if needed." }\end{array}$
\end{tabular}

Collaboration of car-sharing companies and real-estate developers
"For the premise owners, big office buildings, there is a constraint of parking space, so with a sharing scheme, they can offer mobility to the tenants and it adds more value to the premise itself."

"It is a new model. When you buy or rent in a house, there is a service fee, which you have anyway, but in this service fee it is included that there is an electric car in the basement that can be used via shared calendar with other inhabitants. So you know that you don't necessarily need your own car, or you at least don't need a second car."
Business owner

Business owner

Expert

"Starting with a long-term vision: the self-driving car, to some extent it is an end to classic car sharing and the modern way of peer-to-peer car sharing that has come up now. Self-driving car means that you can just hire a car, with your cellphone, just like you hire a taxi. It will come, and it will be electrically powered. It will come, pick you up, drop you off somewhere. If you need to go somewhere else, another car will come, pick you up, drop you off. So it is a very fluent public transport system, that is individualenough so that you can sit there only with your friends, only by yourself, but it is also public enough so that you can access it from everywhere."

$\begin{array}{ll}\text { New mobility } & \text { "In the medium term, car manufacturers will benefit from the emerging markets, but } \\ \text { schemes } & \text { there will be a change in the car industry. The car is losing its status symbol in some } \\ \text { parts of the world, and it is becoming means of transportation. Now the industry is } \\ \text { turning into selling mobility schemes instead of cars, and the impact of e-mobility is } \\ \text { one of the components of the whole industry-widechange." }\end{array}$

Future integrated mobility model
"In the future, car ownership and public transportation are maybe not so separated. The talk is about the travel chain, which means: range of cars, different sizes, maybe also big trains where one can drive small cars. So transportation is becoming flexible."
Expert

Expert 


\section{The Sharing Economy and the Future of Personal Mobility Olga Novikova}

\section{About the Authors}

Olga Novikova is a researcher and $\mathrm{PhD}$ candidate at Hanken School of Economics in Helsinki, Finland. Previously, she has worked on a variety of research projects from electric mobility to business model innovation. Her current research interests are the emergence and implications of the sharing economy. She has also co-founded Experience Living, a hospitality company in the sharing-economy space. Most recently, she has co-founded Good TV, a global mobile channel with a focus on inspiring, educational, and entertaining content.

\section{References}

Agatz, N., Erera, A., Savelsbergh, M., \& Wang, X. 2012. Optimization for Dynamic Ride-Sharing: A Review. European Journal of Operational Research, 223(2): 295-303. http://dx.doi.org/10.1016/j.ejor.2012.05.028

Bauwens, M., Mendoza, N., \& Iacomella, F. 2012. Synthetic Overview of the Collaborative Economy. P2P Foundation.

Belk, R. 2007. Why Not Share Rather Than Own? The Annals of the American Academy of Political and Social Science, 611(1): 126-140. https://doi.org/10.1177/0002716206298483

Belk, R. 2010. Sharing. Journal of Consumer Research, 36(5): 715-734. https://doi.org/10.1086/612649

Belk, R. 2014. You Are What You Can Access: Sharing and Collaborative Consumption Online. Journal of Business Research, 67(8): 1595-1600.

http://dx.doi.org/10.1016/j.jbusres.2013.10.001

Botsman, R. 2013. The Sharing Economy Lacks A Shared Definition. Fast Company, November 21, 2013. Accessed June 15, 2016: http://www.fastcoexist.com/3022028/the-sharing-economy-lacksa-shared-definition

Botsman, R. 2014. Sharing's Not Just for Startups. Harvard Business Review, 92(9): 23-25.

Botsman, R., \& Rogers, R. 2010. What's Mine Is Yours: How Collaborative Consumption is Changing The Way We Live. London, UK: Collins.

Cohen, B., \& Kietzman, J. 2014. Ride On! Mobility Business Models for the Sharing Economy. Organization \& Environment, 27(3): 279-296.

http://dx.doi.org/10.1177/1086026614546199
Expósito-Izquierdo, C., Expósito-Márquez, A., \& Brito-Santana, J. 2017. Mobility as a Service. In H. Song, R. Srinivasan, T. Sookoor, \& S. Jeschke (Eds), Smart Cities: Foundations, Principles, and Applications. Hoboken, NJ: John Wiley \& Sons, Inc. http://dx.doi.org/10.1002/9781119226444.ch15

Hamari, J., Sjöklint, M., \& Ukkonen, A. 2016. The Sharing Economy: Why People Participate in Collaborative Consumption. Journal of the Association for Information Science and Technology, 67(9): 2047-2059. http://dx.doi.org/10.1002/asi.23552

Le Vine, S., \& Polak, J. 2015. Introduction to Special Issue: New Directions in Shared-mobility Research. Transportation, 42(3): 407-411. http://dx.doi.org/10.1007/s11116-015-9603-4

Owyang, J., \& Samuel, A. 2015. The New Rules of the Collaborative Economy: The Threat to Traditional Companies Can't Be Ignored. Vancouver: Vision Critical.

Shaheen, S., \& Chan, N. 2016. Mobility and the Sharing Economy: Potential to Facilitate the First- and Last-Mile Public Transit Connections. Built Environment, 42(4): 573-588.

https://doi.org/10.2148/benv.42.4.573

Shaheen, S., Chan N., \& Gaynor, T. 2016. Casual Carpooling in the San Francisco Bay Area: Understanding User Characteristics, Behaviors, and Motivations. Transport Policy, 51: 165-173. http://dx.doi.org/10.1016/j.tranpol.2016.01.003

Shaheen, S., Chan, N., \& Micheaux, H. 2015. One-Way Carsharing's Evolution and Operator Perspectives from the Americas. Transportation, 42(3): 519-536. http://dx.doi.org/10.1007/s11116-015-9607-0

Shaheen, S., \& Cohen A. 2007. Growth in Worldwide Carsharing: An International Comparison. Journal of the Transportation Research Board, 1992: 81-89.

Shaheen, S., \& Cohen, A. 2013. Carsharing and Personal Vehicle Services: Worldwide Market Developments and Emerging Trends. International Journal of Sustainable Transportation, 7(1): 5-34. http://dx.doi.org/10.1080/15568318.2012.660103

Shaheen, S., Sperling, D., \& Wagner, C. 1998. Carsharing in Europe and North America: Past, Present, and Future. Transportation Quarterly, 52(3): 35-52.

Yin, R. 1994. Case Study Research: Design and Methods. Thousand Oaks, CA: Sage Publications.

Zoepf, S., \& Keith, D. 2016. User Decision-Making and Technology Choices in the U.S. Carsharing Market. Transport Policy, 51: 150-157. http://dx.doi.org/10.1016/j.tranpol.2016.01.010 